\title{
Effects of Sheet Resistance on mc-Si Selective Emitter Solar Cells Using Laser Opening and One-Step Diffusion
}

\author{
Sheng-Shih Wang, ${ }^{1}$ Jyh-Jier Ho, ${ }^{1}$ Jia-Jhe Liou, ${ }^{1}$ Jia-Show Ho, ${ }^{2}$ \\ Song-Yeu Tsai, ${ }^{3}$ Hsien-Seng Hung, ${ }^{1}$ Chi-Hsiao Yeh, ${ }^{4}$ and Kang L. Wang ${ }^{2}$ \\ ${ }^{1}$ Department of Electrical Engineering, National Taiwan Ocean University, No. 2 Peining Road, Keelung 20224, Taiwan \\ ${ }^{2}$ Department of Electrical Engineering, University of California, Los Angeles, CA 90095, USA \\ ${ }^{3}$ Laboratory of Green Energy \& Environment Research, Industrial Technology Research Institute, Hsinchu 31061, Taiwan \\ ${ }^{4}$ Department of Surgery, Chang Gung Memorial Hospital, Keelung 204, Taiwan
}

Correspondence should be addressed to Jyh-Jier Ho; jackho@mail.ntou.edu.tw

Received 28 December 2014; Revised 12 March 2015; Accepted 14 March 2015

Academic Editor: Bing Gao

Copyright (c) 2015 Sheng-Shih Wang et al. This is an open access article distributed under the Creative Commons Attribution License, which permits unrestricted use, distribution, and reproduction in any medium, provided the original work is properly cited.

In order to simplify process procedure and improve conversion efficiency $(\eta)$, we present new steps of laser opening and one-step $\mathrm{POCl}_{3}$ diffusion to fabricate selective emitter (SE) solar cells, in which heavily doped regions (HDR) and lightly doped regions (LDR) were formed simultaneously. For HDR, we divided six cells into two groups for $\mathrm{POCl}_{3}$ diffusion with sheet resistance $\left(R_{S}\right)$ of $40 \Omega / \mathrm{sq}$ (for group A) and $50 \Omega / \mathrm{sq}$ (for group B). The dry oxidation duration at a temperature of $850^{\circ} \mathrm{C}$ was 18,25 , and $35 \mathrm{~min}$ for the 3 different cells in each group. This created six SE samples with different $R_{S}$ pairings for the HDR and LDR. The optimal cell (sample SE2) with $R_{S}$ values of $40 / 81 \Omega / \mathrm{Sq}$ in HDR/LDR showed the best $\eta$ of $16.20 \%$, open circuit voltage $\left(V_{\mathrm{OC}}\right)$ of $612.52 \mathrm{mV}$, and fill factor (FF) of $75.83 \%$. The improvement ratios are $1.57 \%$ for $\eta$ and $14.32 \%$ for external quantum efficiency (EQE) as compared with those of the two-step diffusion process of our previous study. Moreover, the one-step laser opening process and omitting the step of removing the damage caused by laser ablation especially reduce chemistry pollution, thus showing ecofriendly process for use in industrial-scale production.

\section{Introduction}

For the purpose of promoting the wide use of solar cells, the photovoltaic industry has recently investigated solar cells with higher conversion efficiency and lower cost. Chemical waste pollution from solar cell production will be harmful to the environment. The potential of selective emitter (SE) in crystalline silicon solar cell technology has been proved for many years. The production of selective emitter solar cells is a promising technology and has attracted considerable attention in solar cell research. An interesting feature of SE cells is their structure, with heavily doped regions (HDR) beneath the metal contacts on the front surface and lightly doped regions (LDR) between the contact fingers [1]. The SE structure combines the advantages of shallow and deep emitter layers in c-Si solar cells [2]. SE structure can lower contact resistance resulting from the heavy doping of the regions and improve the passivation of the front surface in the LDR in the interstices of the electrode grid. In addition to reducing contact recombination, which increases solar conversion efficiency, SE cells offer a good response at shortwavelength spectrum.

Lasers have wide applications in industrial processes such as welding, cutting, drilling, ablation deposition, and surface treatment [3]. They are now also in widespread use in the photovoltaic industry, for applications such as surface texturization [4], laser scattering tomography [5], laser doping of selective emitter cells [6], laser grooving [7], and laser chemical processing [8]. Laser opening can be successfully used in SE solar cell fabrication, avoiding 
the standard photolithography step. A detailed analysis and further discussion of the laser opening process can be found in [9]. The SE structure can be implemented using double diffusion [10] or one-step diffusion together with wet backetching of the cell area between the fingers [11]. This one-step diffusion (sometimes known as one-step) is a commonly used technique. In the past, several authors proposed different uses for one-step diffusion, such as one-step screen-printing [12], one-step rapid thermal diffusion [13], and single high temperature step [14].

In our previous research [15], two-step $\mathrm{POCl}_{3}$ diffusions and laser opening were adopted on the large-area multicrystalline silicon (mc-Si) solar cells to improve the $\mathrm{SE}$ performance. That gives an optimal conversion efficiency of $15.95 \%$ and external quantum efficiency (EQE) of $68.6 \%$. In the present study, we combine the advantages of SE, laser opening, and one-step $\mathrm{POCl}_{3}$ diffusion in the fabrication of solar cells using equipment already established in the industrial production. Furthermore, we are going to produce SE mc-Si solar cells without a damage removal process. Thus, in our study, both the lightly doped emitter and the heavily doped contact areas were simultaneously formed in the same diffusion method. This selective doping especially is achieved without the need of masking steps, multiple diffusions, photolithography, or back-etching techniques [16]. We then investigate the effect of different dry oxidation durations on the performances of mc-Si solar cells. This variable for oxidation duration induces different sheet resistances $\left(R_{S}\right)$ for the LDR. The proposed process is expected to simplify the chemical aspect of the manufacturing process, which would decrease environment pollution and produce low-cost, highefficiency solar cells.

\section{Experiments}

For the fabrication of mc-Si solar cells as in our previous studies [9, 17], p-type (100) oriented $\mathrm{Si}$ with a resistivity of $1 \Omega-\mathrm{cm}$ and dimensions of $156 \times 156 \mathrm{~mm}^{2}$ was used as the substrate. This wafer had a thickness of approximately $200 \mu \mathrm{m}$. An Nd:YAG laser $(\lambda=532 \mathrm{~nm})$ with a pulse duration of $30 \mathrm{~ns}$ melted the barrier layer on the wafer surface to accommodate metal contacts. To investigate the characteristics of the developed SE mc-Si, the current density-voltage $(J-V)$ curves of the developed devices were measured using a solar simulator (Wacom, WXS-220S-L2) at AM 1.5 and illuminated at $1000 \mathrm{~W} / \mathrm{m}^{2}$ by an induced $J-V$ tester (Keithley, 4200). The minority carrier lifetime (surface passivation quality) was assessed by lifetime measurements (Semilab, WT2000). In addition, the contact resistance and the light-beaminduced current (LBIC) were measured using a CoRRescan instrument (MRN-061), and an incident-photon-to-currentefficiency (IPCE) system (PV Measurements, QEX7) was used to measure values of EQE.

Figure 1 shows a flow chart of the fabrication process for the SE samples. The first step is surface texturization, which reduces the effective optical losses of commercial solar cells. In this study, an $\mathrm{HF} / \mathrm{HNO}_{3}$ acid solution was used for texturing the mc-Si material. With a thermal oxidation step at $850^{\circ} \mathrm{C}$ of different durations, silicon dioxide $\left(\mathrm{SiO}_{2}\right)$ is deposited as the diffusion barrier layer, which also passivates the pn-junctions at the surface of the cell [18]. The passivation of highly $n^{+}$-doped silicon using $\mathrm{SiO}_{2}$ is more effective than that using $\mathrm{SiN}_{X}$ [19]. The one-step $\mathrm{POCl}_{3}$ diffusion was performed after laser opening to simultaneously form the HDR and LDR that make up a SE cell. After the antireflection layer of $\mathrm{SiN}_{X}$ is formed by plasma-enhanced chemical vapor deposition (PECVD) on the $\mathrm{SiO}_{2}$ layer, an $\mathrm{Al}$-paste is screen printed onto the solar cells to form a metallic contact layer. Finally, to avoid shunts between the front and the rear sides, we applied laser edge isolation.

To investigate the effect of different emitter $R_{S}$ pairs on the cell performance, we divided six cells into two groups for different levels of $\mathrm{POCl}_{3}$ diffusion, with $R_{S}$ of $40 \Omega$ /sq (group A) and $50 \Omega /$ sq (group B) in HDR (as shown in Figure 1). The dry oxidation step was applied to each group of cells at a temperature of $850^{\circ} \mathrm{C}$ for durations of 18,25 , and $35 \mathrm{~min}$, which correspond to samples SE1/SE4, SE2/SE5, and SE3/SE6. Subsequently, $\mathrm{SiO}_{2}$ layers of different thicknesses, 7, 10, and $12 \mathrm{~nm}$, were deposited on the top surface for the SE1/SE4, SE2/SE5, and SE3/SE6 samples, respectively. The emitter $R_{S}$ varies with the thickness of the $\mathrm{SiO}_{2}$ layer.

Laser ablation with a power of $2 \mathrm{~J} / \mathrm{cm}^{2}$ was used to create openings in the $\mathrm{SiO}_{2}$ layer; this step performs the function of photolithography. This creates HDR of the mcSi substrate under the contact fingers. During the one-step $\mathrm{POCl}_{3}$ diffusion process, the laser-ablated regions acquire heavy $n^{+}$-type doping, leaving light $n$-type doping areas under the barrier layers. This generates the SE structure. For the purpose of reducing chemical pollution in production of solar cells, our process for SE solar cell production excludes the step of removing damage produced by laser ablation.

It should be emphasized that the step of omitting damage removal has also some drawbacks. For the purpose of improving electrical characteristics, the irradiated region of a silicon substrate is lifted off by the expansion of the molten and vaporized Si. Note that the recombination losses were increased after the laser ablation process due to laserinduced defects on the c-Si surface. Alkaline solution $(\mathrm{KOH}$ or $\mathrm{NaOH}$ ) was used to remove these damages after laser ablation process, which can be confirmed by the lifetime measurement.

\section{Results and Discussion}

In order to remove thermal oxide $\left(\mathrm{SiO}_{2}\right)$ as the diffusion barrier layer, the developed laser-opening process needs to melt $\mathrm{Si}$ surface because of low light absorption of thermal $\mathrm{SiO}_{2}$. Figure 2 illustrates the scanning electron microscopy (SEM) image of solar cell with laser fluence of $2 \mathrm{~J} / \mathrm{cm}^{2}$. The laser opening process must be carried out by carefully controlling the laser scanning parameters to maintain the metallic contact lines within a width of approximately $100 \mu \mathrm{m}$. A distinct surface morphology is evident within the region of laser ablation. The diffusion barrier absorbs the heat and irradiation emitted by the laser for approximately $10 \mathrm{~ns}$. The temperature then quickly increases to melting point 


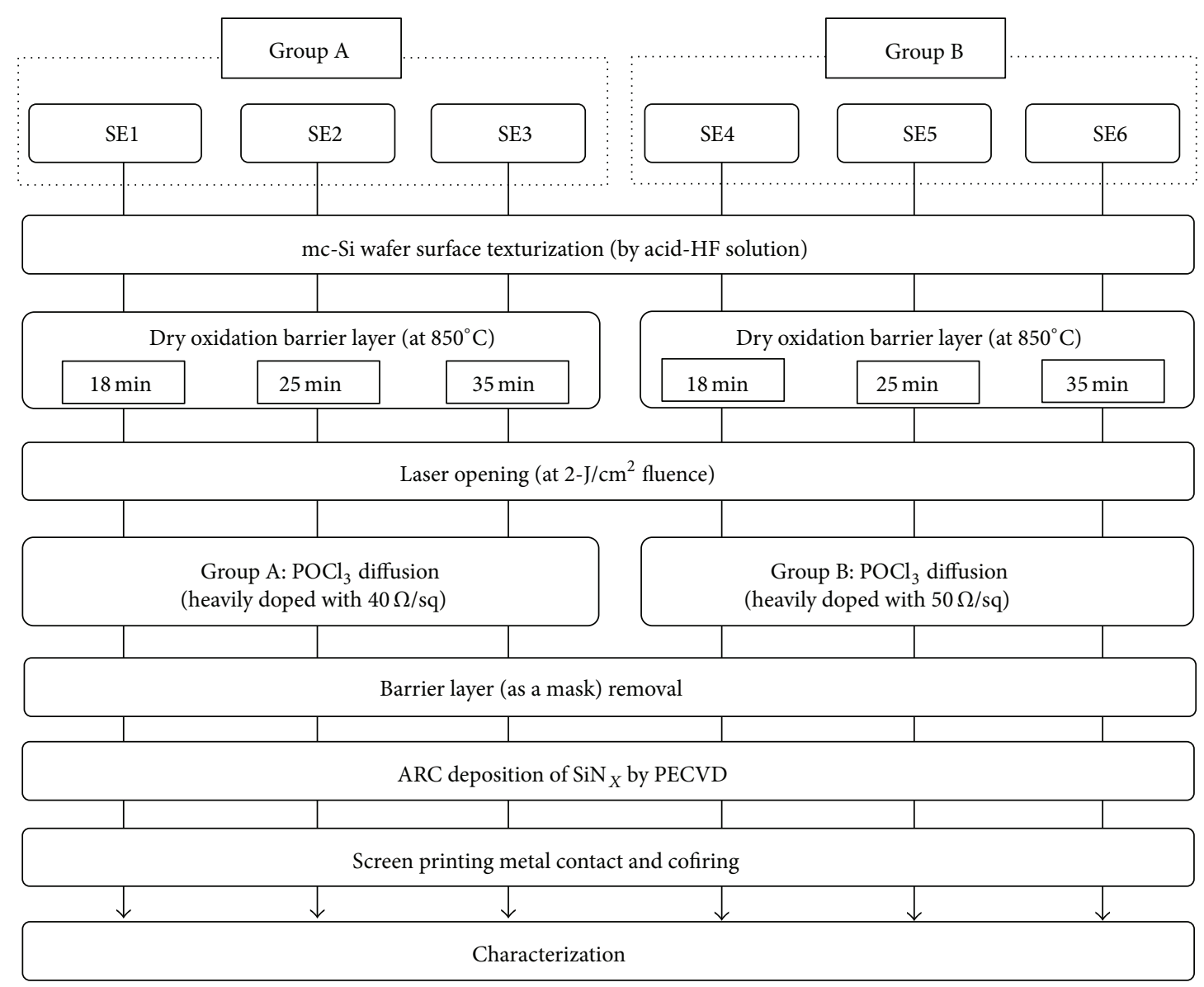

FIGURE 1: Fabrication procedure for six SE samples prepared to investigate the effects of dry oxidation duration and one-step $\mathrm{POCl}_{3}$ diffusion on solar cell performance. The heavily doped regions and lightly doped regions were formed simultaneously with one-step $\mathrm{POCl}_{3} \mathrm{diffusion}_{\text {. }}$

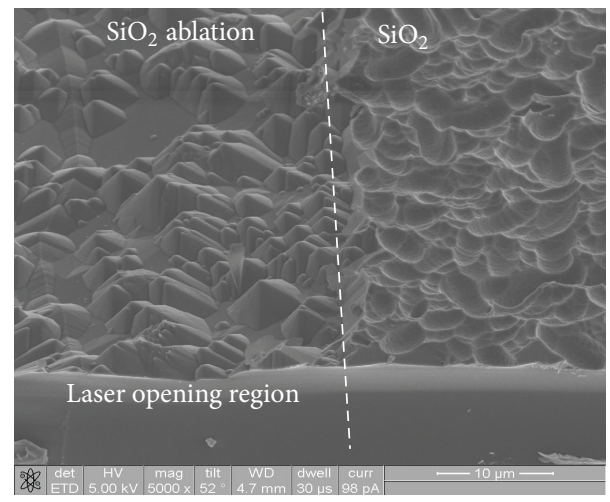

FIGURE 2: SEM image of the mc-Si substrate after laser opening with the fluence of $2 \mathrm{~J} / \mathrm{cm}^{2}$, in which the laser-irradiation duration is $10 \mathrm{~ns}$ approximately.

(approximately $1417^{\circ} \mathrm{C}$ ). Obviously, the ablated $\mathrm{SiO}_{2}$ region (left-side image) shows the random pyramid structure, after laser damage is removed by $\mathrm{KOH}$ solution, in the preselected region for heavy doping.
Contact resistance is a key factor in the conversion efficiency for low-cost, high-efficiency solar cells, regardless of device type, and it is the most critical performance parameter for solar cells [20]. After one-step $\mathrm{POCl}_{3}$ diffusion, the emitter $R_{S}$ pairs for HDR and LDR in $\Omega /$ sq units for six samples are (40/75) for SE1, (40/81) for SE2, (40/96) for SE3, (50/83) for SE4, (50/91) for SE5, and (50/105) for SE6.

Figure 3 illustrates the variation of emitter $R_{S}$ and $\mathrm{SiO}_{2}$ barrier layer thickness. It can be seen that the $R_{S}$ values for the LDR increase monotonically with increasing dry oxidation time. We attribute this to an increased barrier-layer thickness with longer dry oxidation durations. This effect is significant because increasing the dry oxidation time causes the barrierlayer thicknesses to increase, consequently increasing the $R_{S}$. Both $R_{S}$ and barrier layer thickness are represented as functions of dry oxidation duration, which are 18,25 , and $35 \mathrm{~min}$.

The average lifetimes of the six samples, measured at different check points in the process flow described in Figure 1, are shown in Figure 4 and Table 1. These allow us to survey the effect of laser ablation on minority carrier recombination. The average lifetime of the mc-Si wafers after surface texturization (acid etching) is about $7 \mu \mathrm{s}$. After the 
TABLE 1: Average lifetime of six SE samples at different check-point stages, which are surface texturization, dry oxidation, laser opening and mask removal, and $\mathrm{POCl}_{3}$ diffusion with $\mathrm{ARC}$ deposition, separately. $R_{\mathrm{SH}}$ is heavily doped sheet resistance, and $R_{\mathrm{SL}}$ is lightly doped sheet resistance $(\Omega / \mathrm{sq})$; values inside parentheses are measured.

\begin{tabular}{lcccc}
\hline \multirow{2}{*}{$R_{\mathrm{SH}} / R_{\mathrm{SL}}(\Omega / \mathrm{sq})$} & \multicolumn{3}{c}{ Average lifetime $(\mu \mathrm{s})$, one significant digit } \\
& Surface texturization & Dry oxidation & Laser opening and mask removal & POCl $_{3}$ diffusion/ARC deposition \\
\hline $40 / 75$, for SE1 & 7 & 7.2 & 5.5 & $8.3,(8.339)$ \\
40/81, for SE2 & 7 & 7.6 & 5.9 & $8.7,(8.707)$ \\
40/96, for SE3 & 7 & 7.8 & 7.1 & $9.2,(9.168)$ \\
$50 / 83$, for SE4 & 7 & 7.2 & 5.5 & $8.2,(8.236)$ \\
$50 / 91$, for SE5 & 7 & 7.6 & 5.9 & $8.7,(8.723)$ \\
$50 / 105$, for SE6 & 7 & 7.8 & 7.1 & $9.3,(9.313)$ \\
\hline
\end{tabular}

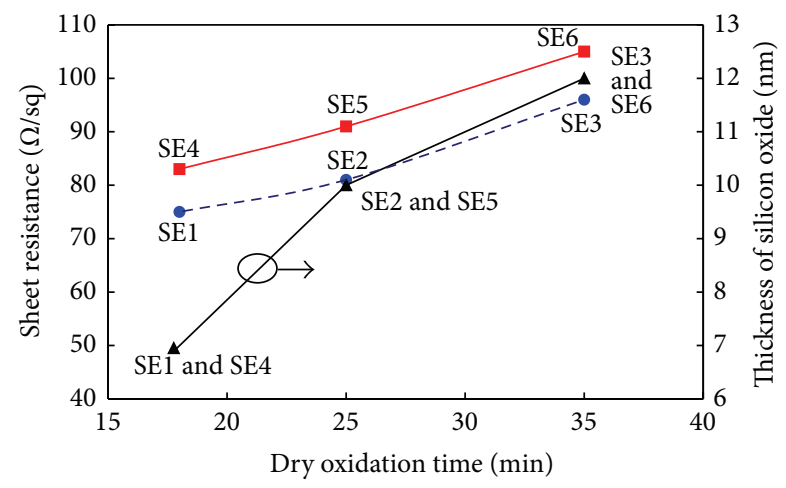

- Diffusion with sheet resistance of $40 \Omega / \mathrm{sq}$
$\rightarrow$ Diffusion with sheet resistance of $50 \Omega / \mathrm{sq}$
$\rightarrow$ Thickness of dry oxide

FIGURE 3: Variation of emitter sheet-resistances and thickness of barrier layer $\mathrm{SiO}_{2}$ versus dry oxidation duration of six SE cells after one-step $\mathrm{POCl}_{3}$ diffusion. The duration for SE1 and SE4 is $18 \mathrm{~min}$, that for SE2 and SE5 is $25 \mathrm{~min}$, and that for SE3 and SE6 is $35 \mathrm{~min}$.

dry oxidation process for SE1/SE4, SE2/SE5, and SE3/SE6, the average lifetime is slightly increased to the range from 7 to $8 \mu \mathrm{s}$, and the increase is higher for longer dry oxidation times. This result of surprisingly low lifetime may be due to the fact that the thickness of $\mathrm{SiO}_{2}$ mask of six samples is thinner than $13 \mathrm{~nm}$ and the passivation effort of $\mathrm{SiO}_{2}$ is not better. The reason needs more studying. All of the average lifetimes after step of laser opening obviously drop owing to omitting the step of laser-induced damage removal which is based on the consideration of reducing chemistry pollution. Comparing Figures 3 and 4, for laser opening, $\mathrm{POCl}_{3}$ diffusion, and ARC-SiN ${ }_{X}$ deposition, the variation tendencies of average lifetimes for SE1-SE2-SE3 and SE4-SE5-SE6 are similar to that of emitter $R_{S}$. This confirms that the longer dry oxidation time is responsible for the increased lifetime, as described in Figure 3. Furthermore, the longest average lifetime is $9.3 \mu \mathrm{s}$ for SE6 with heavily doped sheet resistance $\left(R_{\mathrm{SH}}\right)=50 \Omega / \mathrm{sq}$ for HDR and lightly doped sheet resistance $\left(R_{\mathrm{SL}}\right)=105 \Omega / \mathrm{sq}$ for LDR, as indicated in Table 1 . The $R_{S}$ of both the heavily and lightly doped regions of SE6 are the greatest among the six cells. The longest average lifetime of SE6 implies that SE6 also has the lowest surface recombination velocity. On the other hand, the average measured lifetimes after laser

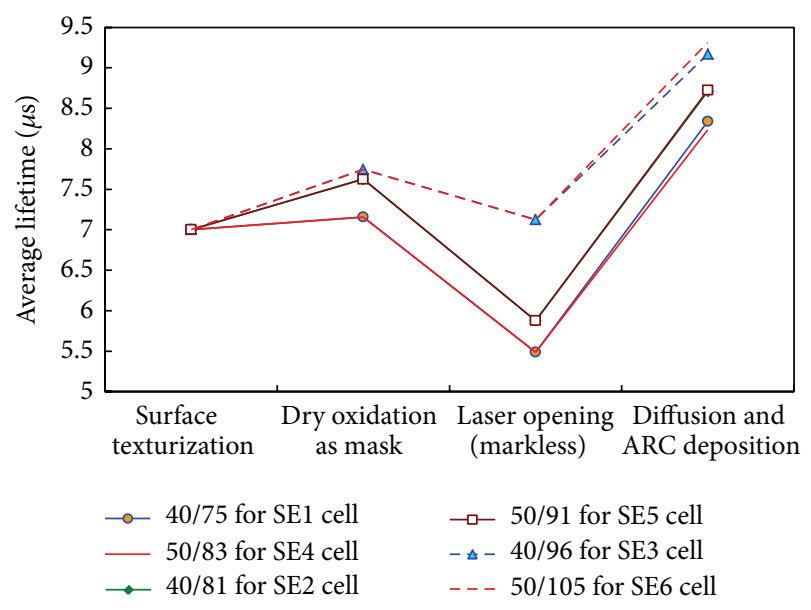

FIGURE 4: The variation of the average lifetime of six mc-Si wafers at different processing steps.

opening are less than that before laser opening, confirming that laser ablation results in a reduction in the effective lifetime of the samples [21].

The optic-electrical performance parameters of the six mc-Si SE solar cells developed in this study are listed in Table 2. SE2 has the largest open circuit voltage $\left(V_{\mathrm{OC}}\right)$ value, at $612.52 \mathrm{mV}$, while SE6 has the largest current density of short circuit $\left(J_{\mathrm{SC}}\right)$ value, at $35.16 \mathrm{~mA} / \mathrm{cm}^{2}$, as well as the greatest effective lifetime.

Contact resistance losses occur at the interface between the $\mathrm{Si}$ and metal contact layers. In addition to affecting the performance of cells, contact resistance significantly influences their $J-V$ characteristics. The primary impact of increased series resistance is the reduction in fill factor $(\mathrm{FF})$, which is a parameter describing the total conversion efficiency $(\eta)$ [20]. Experimental measurements show that, owing to the difference in emitter $R_{S}$ between SE2 and SE6, higher FF compensates for a slightly lower $J_{\mathrm{SC}}$. The best $\eta$ value of $16.20 \%$ and EQE of $78.42 \%$ were obtained for the SE2 cell, which is better than that of our previous study by two-step $\mathrm{POCl}_{3}$ diffusion where values of $\eta$ and $\mathrm{EQE}$ are $15.95 \%$ and $68.6 \%$, respectively [15]. For the optimal SE2 cell of one-step process in this research, the improvement ratios are $1.57 \%$ for $\eta$ and $14.32 \%$ for $\mathrm{EQE}$ as compared 
TABLE 2: Solar-cell performance parameters of six SE samples with different heavily doped sheet resistance $\left(R_{\mathrm{SH}}\right)$ and lightly doped sheet resistance $\left(R_{\mathrm{SL}}\right)$, fabricated using one-step $\mathrm{POCl}_{3}$ diffusion.

\begin{tabular}{|c|c|c|c|c|c|}
\hline Sample number & $R_{\mathrm{SH}} / R_{\mathrm{SL}}(\Omega / \mathrm{sq})$ & $V_{\mathrm{OC}}(\mathrm{mV})$ & $J_{\mathrm{SC}}\left(\mathrm{mA} / \mathrm{cm}^{2}\right)$ & $\mathrm{FF}(\%)$ & $\eta(\%)$ \\
\hline SE1 & $40 / 75$ & 612.11 & 34.81 & 75.51 & 16.09 \\
\hline SE2 & $40 / 81$ & 612.52 & 34.87 & 75.83 & 16.20 \\
\hline SE3 & $40 / 96$ & 610.55 & 34.94 & 73.79 & 15.74 \\
\hline SE4 & $50 / 83$ & 611.63 & 34.86 & 75.34 & 16.06 \\
\hline SE5 & $50 / 91$ & 611.87 & 35.03 & 72.63 & 15.57 \\
\hline SE6 & $50 / 105$ & 610.51 & 35.16 & 67.02 & 14.39 \\
\hline
\end{tabular}

with the two-step process. A large number of defects are known to form recombination centers; therefore, the laserinduced damage was removed in [21]. In contrast to those studies, our method excludes the step of removing damage caused by laser ablation. Therefore, our method produces less environmentally detrimental chemical waste. The longest average lifetime $(9.3 \mu \mathrm{s})$ for SE6 does not correlate with the best conversion efficiency (16.20\%) in SE2; therefore, the lifetime and conversion efficiency in this experiment do not seem to be related.

The $J-V$ characteristics of SE mc-Si solar cells (SE1SE6) with different emitter $R_{S}$ are plotted in Figure 5, which were measured under standard conditions (AM 1.5 spectra, $1000 \mathrm{~W} / \mathrm{m}^{2}$, and $25^{\circ} \mathrm{C}$ ). The insets are enlarged $J_{\mathrm{SC}}$ and $V_{\mathrm{OC}}$ sections for easier observation and comparison. The curves of Figure 5, except that of SE6, are difficult to distinguish. On observing the enlarged insets of Figure 5, we found that SE2 has the largest value for $V_{\mathrm{OC}}$, while the largest value for $J_{\mathrm{SC}}$ was obtained for SE6. The $J-V$ characteristics for the six SE samples are consistent with the parameters listed in Table 2. Contact resistance losses occur at the interface between the $\mathrm{Si}$ and the metal contact, which can affect the cell performance. Contact resistance has a significant effect on the currentvoltage characteristics of the cell.

The resulting EQE curves and their average values for six different SE samples for short-wavelength (300-600 nm) light are plotted in Figure 6. In order to clearly compare EQE of the six SE solar cells for the blue response region (300 to $600 \mathrm{~nm}$ ), we omit the red response (above $600 \mathrm{~nm}$ ) portion of the spectral response curves.

All six cells differed significantly in EQE, which was primarily influenced by surface recombination and the film thickness of the surface-barrier [22]. For short wavelengths, SE5 has the highest average EQE (91.7\%), but the averages of the curves of all six cells for red response (wavelength above $600 \mathrm{~nm}$ ) are similar. Enhanced blue response is consistent with the theory that the low surface doping concentrations result in reduced electron-hole pair recombination in the emitter region [21]. The spectral range of EQE data has been limited to the region in which the contribution of the emitter is evident. The data also clarifies that EQE values increase for the blue region of the impinging sun spectrum with thinner emitter thickness [23]. The EQE of SE5 was always larger than the others for wavelengths between $410 \mathrm{~nm}$ and $600 \mathrm{~nm}$. Further experiments have to be conducted to identify the

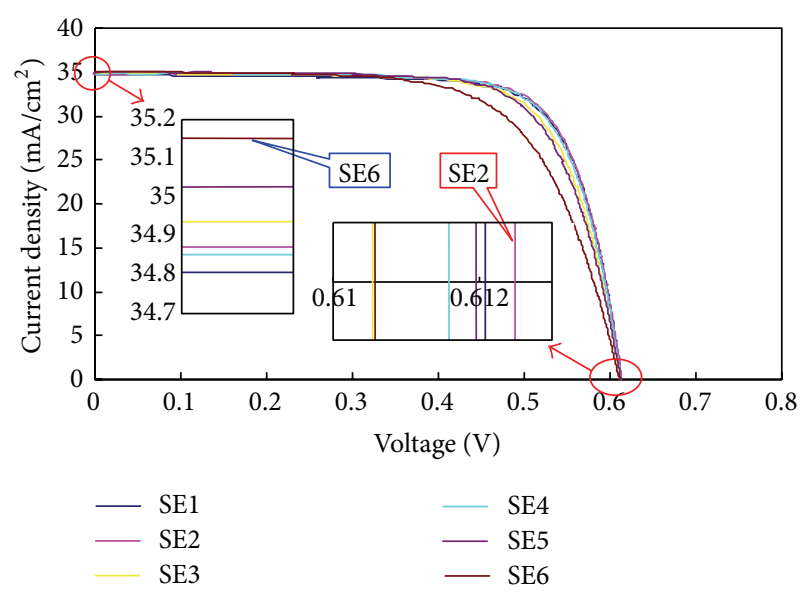

Figure 5: Current density-voltage $(J-V)$ characteristics of SE mcSi solar cells with different emitter-region sheet resistances under standard measuring conditions (AM 1.5 spectra, $1000 \mathrm{Wm}^{-2}$, and $25^{\circ} \mathrm{C}$ ). The insets are enlargements of the $J_{\mathrm{SC}}$ and $V_{\mathrm{OC}}$ sections.

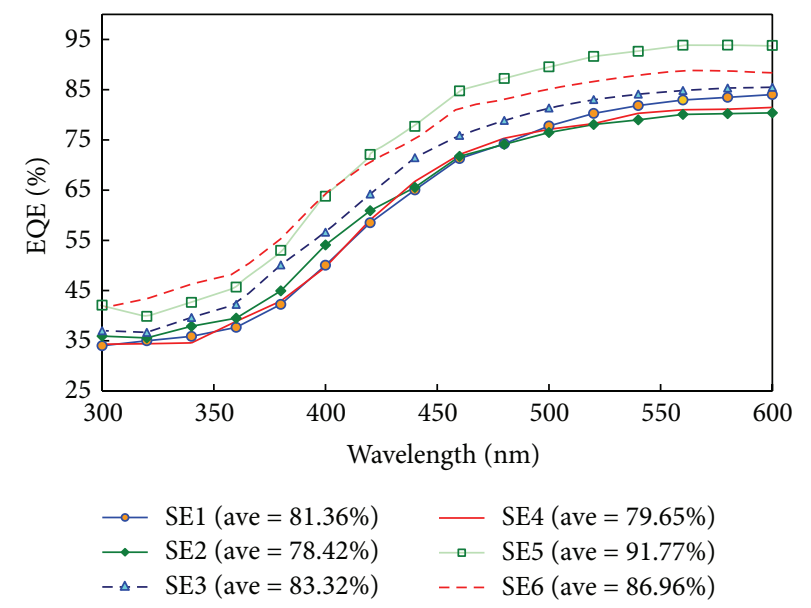

FIGURE 6: External quantum efficiency (EQE) and their average values for six different SE samples for short-wavelength (300$600 \mathrm{~nm}$ ) light.

difference on EQE curves between selective emitter and homogeneous emitter.

In order to investigate the percentage of occupied minority carriers on the cell surface, Figure 7 shows the distribution 


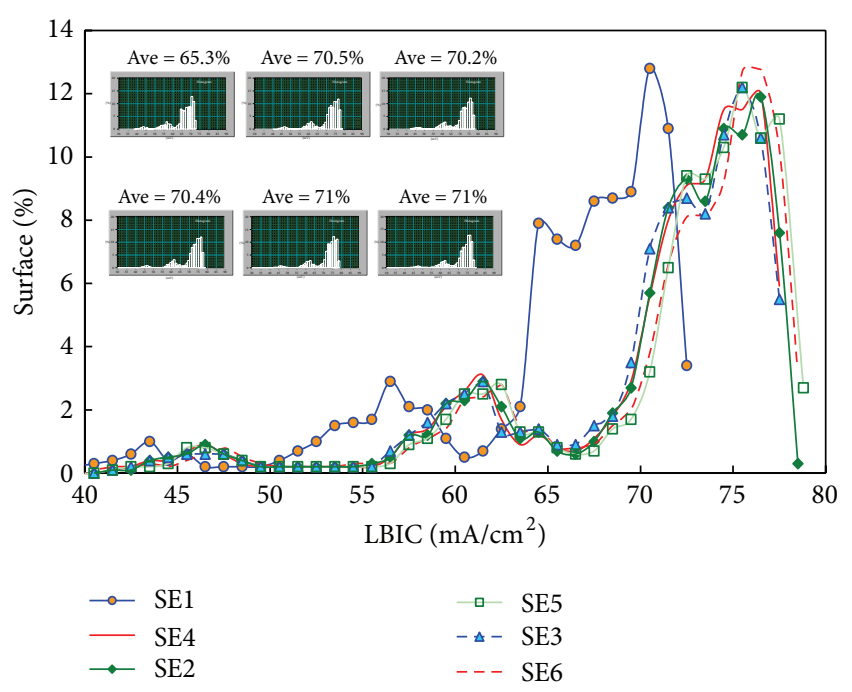

FIgURE 7: Comparison with LBIC $\left(\mathrm{mA} / \mathrm{cm}^{2}\right)$ of the occupied minority carriers (\%) and average values (\%) on surface of six SE samples. The inset histograms are real-distribution profiles of corresponding LBIC density.

profiles and corresponding average values of LBIC for the six SE mc-Si solar cells. The average LBIC values increase with $R_{S}$ (except for cell SE2), which can be attributed to the increase in lifetime with increased emitter $R_{S}$, as presented in Figure 4. It is evident that $\operatorname{SE1}(40 / 75 \Omega / \mathrm{sq})$ shows the lowest average LBIC value of $65.3 \%$, which corresponds its $J_{\mathrm{SC}}$ value of $34.81 \mathrm{~mA} / \mathrm{cm}^{2}$ presented in Table 2 .

Figure 8(a) presents the distribution profile and corresponding average values of contact resistance for the six SE mc-Si solar cells. Mappings of contact resistance for all the SE mc-Si solar cells are presented in Figure 8(b). The color in center area of the image becomes white as the pairs of $R_{S}$ increase. This relates the occupied series resistance (in \%) on the cell surface to conversion efficiency. The low contact resistance of the six samples can be attributed to low emitter $R_{S}$, which leads to an increase in the FF. For SE6, the highest emitter $R_{S}$ pair with $50 / 105 \Omega /$ sq increased contact resistance to an average of $39.6 \%$ and reduces FF to $67.2 \%$. The white regions of the mapping images indicate high contact resistance. Blue regions, indicating low contact resistance, account for the enhanced conversion efficiency. For the two-group fabrication condition of the developed mc$\mathrm{Si}$ solar cells in Figure 1, the larger $R_{S}$ produced higher average values (23.6\% for SE3, 39.6\% for SE6) for the white mapping regions in the distribution profile, thus causing these cells to have the lowest conversion efficiencies (as presented in Table 2).

Figure 9(a) shows the potential loss (in $\mathrm{mV}$ ) scanned from the potential gradient of the current flowing through the emitter area of the developed SE mc-Si solar cells. The overall difference in the average potential loss across all six solar cells was $2.5 \%$. However, steady-state response and the color distribution of the mapping images, shown in Figure 9(b), do not show obvious differences between the cells. Regions of white and orange in the maps of potential loss for the surfaces disappear gradually as the emitter $R_{S}$ increases. Furthermore, the variation tendency of average potential losses for each group is inversely proportional to that of the corresponding $R_{S}$. The increased potential loss for SE mc-Si solar cells can be attributed to the low emitter saturation current density $\left(J_{\mathrm{oe}}\right)$ in tandem with the lower $R_{S}$ of the emitter layer and recombination in space charge regions without a laserdamage removal process, thus reducing $V_{\mathrm{OC}}$.

\section{Conclusions}

In this paper, we explored the influence of $R_{S}$ on SE solar cells fabricated using laser opening and one-step $\mathrm{POCl}_{3}$ diffusion. The best conversion efficiency $16.20 \%$ was obtained for the SE2 cell, with a $V_{\mathrm{OC}}$ of $612.52 \mathrm{mV}$ and FF of $75.83 \%$, which are the largest among the six samples. SE2 features a solar cell emitter with $R_{S}$ pair of $40 \Omega / \mathrm{Sq}$ in the HDR and $81 \Omega / \mathrm{Sq}$ in the LDR. The longest lifetime of $9.3 \mu \mathrm{s}$ was observed in SE6, which also exhibited the largest $J_{\mathrm{SC}}$, $35.16 \mathrm{~mA} / \mathrm{cm}^{2}$. Furthermore, by comparing the data presented in Figure 4, Table 2, and Figure 6, no clear relationship was found between average lifetime, $J-V$ parameters, and EQE for the six cells. The thickness of the passivation layer, formed by thermal oxidation steps with different durations, clearly affects the characteristics of SE mc-Si solar cells.

Six SE mc-Si solar cells with different emitter $R_{S}$ by one-step $\mathrm{POCl}_{3}$ diffusion were investigated. We were able to produce SE mc-Si solar cells without a damage removal process and with conversion efficiency up to $16.20 \%$, indicating that the effect of laser-induced damage (of defects and dislocations) for low laser power $\left(2 \mathrm{~J} / \mathrm{cm}^{2}\right)$ is slightly minor. The optimal emitter $R_{\mathrm{S}}$ is a compromise between series resistance and carrier lifetime. On the other hand, SE mc-Si solar cells have significantly improved FF owing to the microstructure of the opening regions.

In the one-step process of this research, the best $\eta$ value of $16.20 \%$ and EQE value of $78.42 \%$ were obtained for the SE2 cell, which is better than that of our previous study by twostep $\mathrm{POCl}_{3}$ diffusion with $\eta$ value of $15.95 \%$ and $\mathrm{EQE}$ value of $68.6 \%$. Therefore, the one-step laser opening process exhibits simplicity, reliability, high speed, and cost effectiveness and especially reduces chemistry pollution within fabrication of solar cells; thus, this process shows promise for use in industrial-scale production.

\section{Conflict of Interests}

The authors declare that there is no conflict of interests regarding the publication of this paper.

\section{Acknowledgments}

The authors acknowledge the assistance and partial financial support of Ministry of Science and Technology (NSC 1022221-E-019-040-MY3) and Chang Gung Memorial Hospital (CMRPG 2B0511, CMRPG 2B0521, CMRPG 2B0531, and 


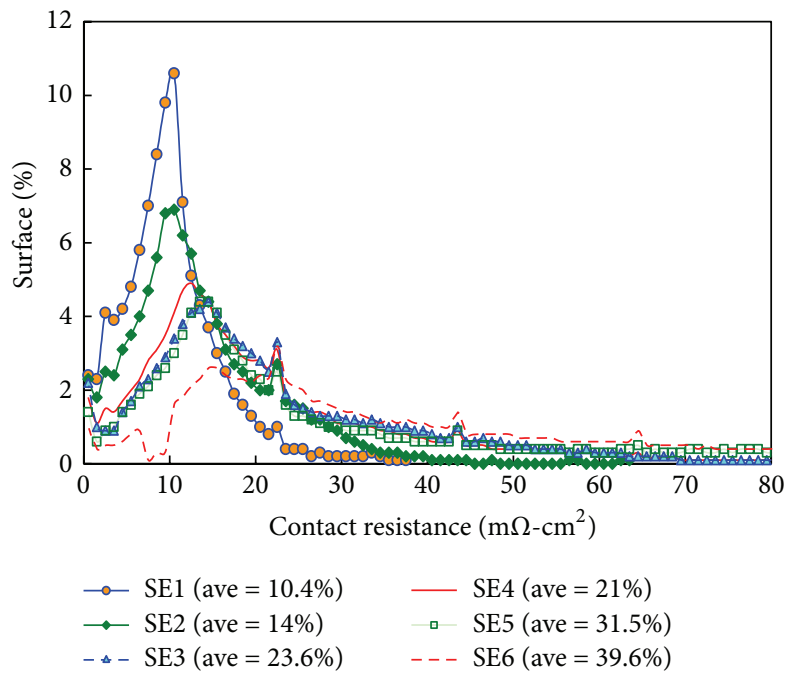

(a)
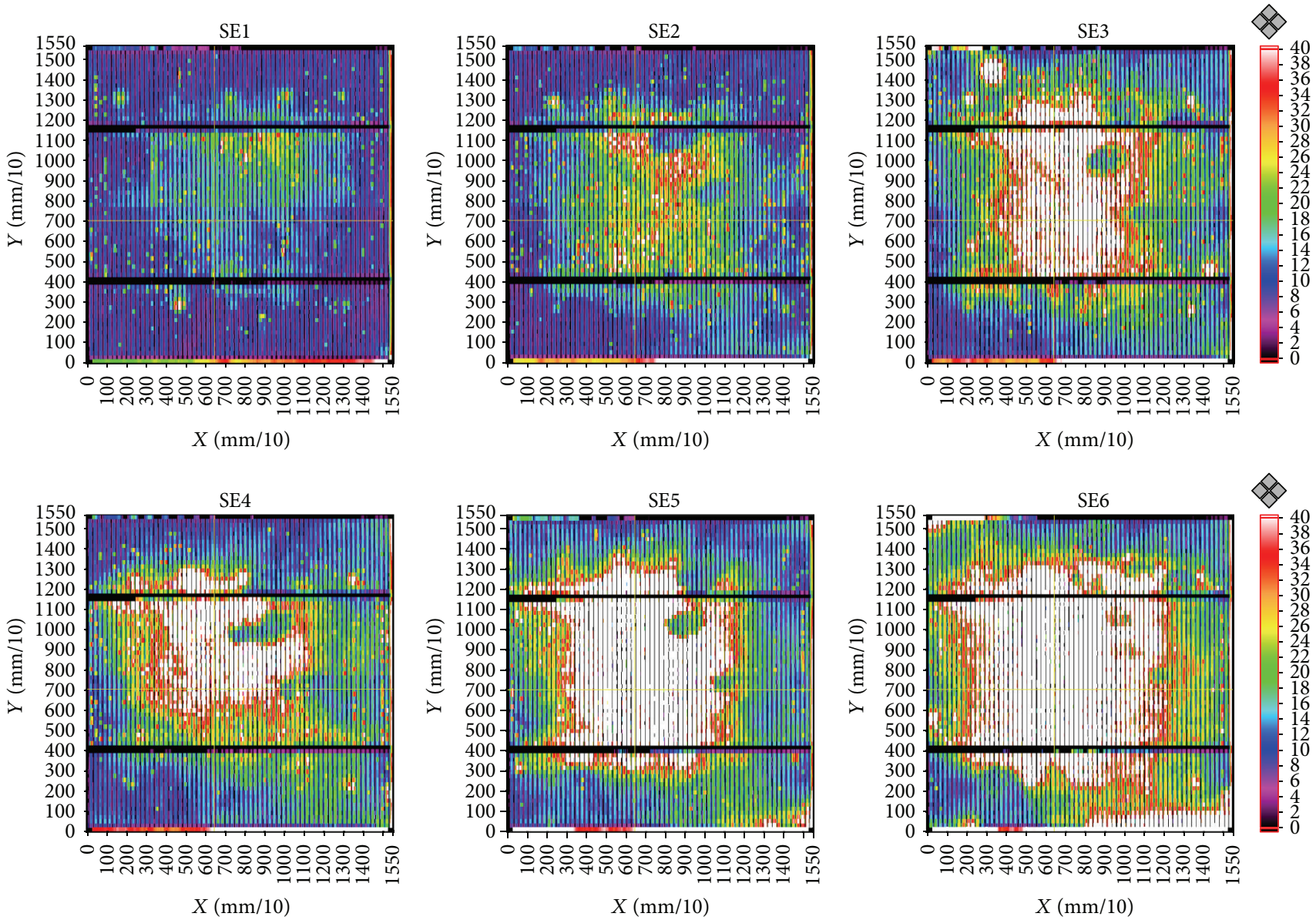

(b)

FIGURE 8: (a) Comparison of contact resistance $\left(\mathrm{m} \Omega-\mathrm{cm}^{2}\right)$ with the average percentage of occupied surface minority carriers (\%) for six SE samples and (b) corresponding real-distribution maps of contact resistance profiles. The left-down point is the origin of $X-Y$ coordinates which means the scan size of cells, from 0 to 1500 (extreme $=1550$ ) with interval of 100 , and scale is $\mathrm{mm} / 10$. The right $y$-axis (color chart) represents resistance values (in $\left.\mathrm{m} \Omega-\mathrm{cm}^{2}\right)$, from bottom ( 0 for dark purple) to top (40 for bright red) with interval of 2 . 


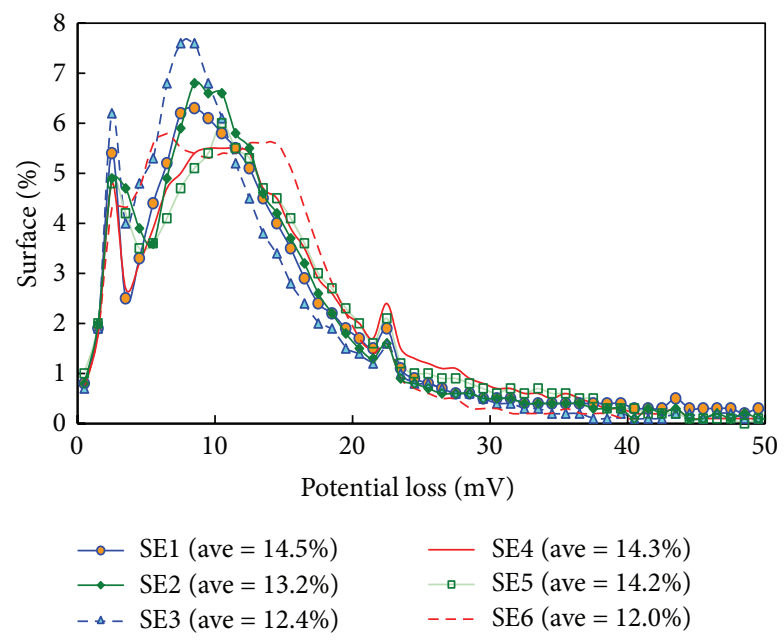

(a)
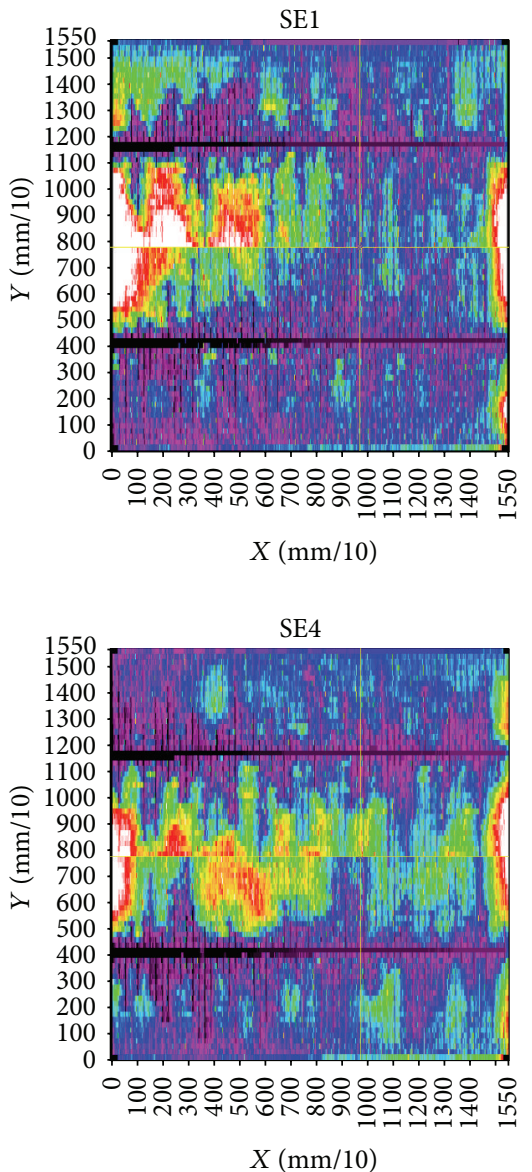
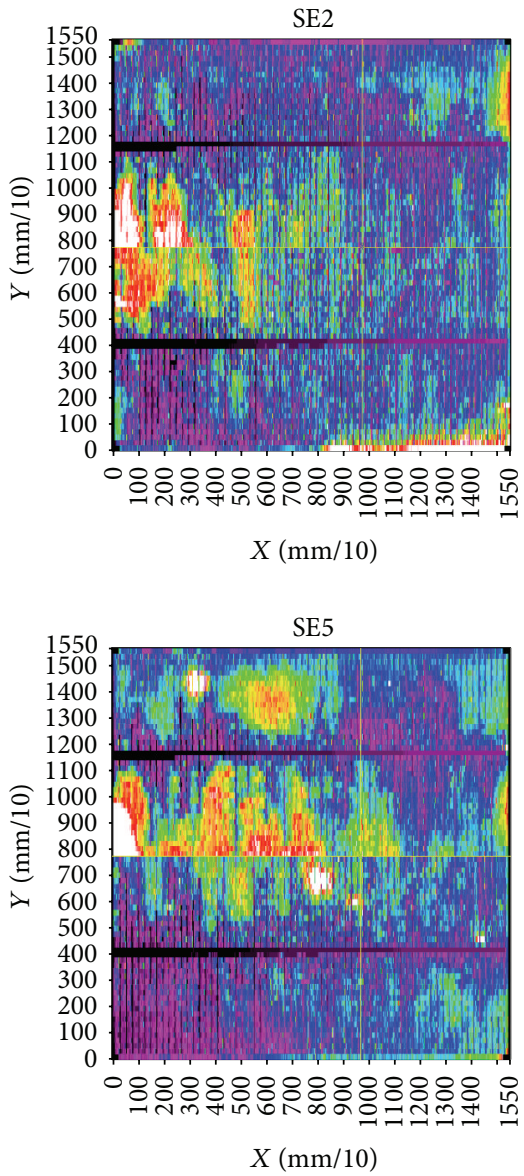

(b)
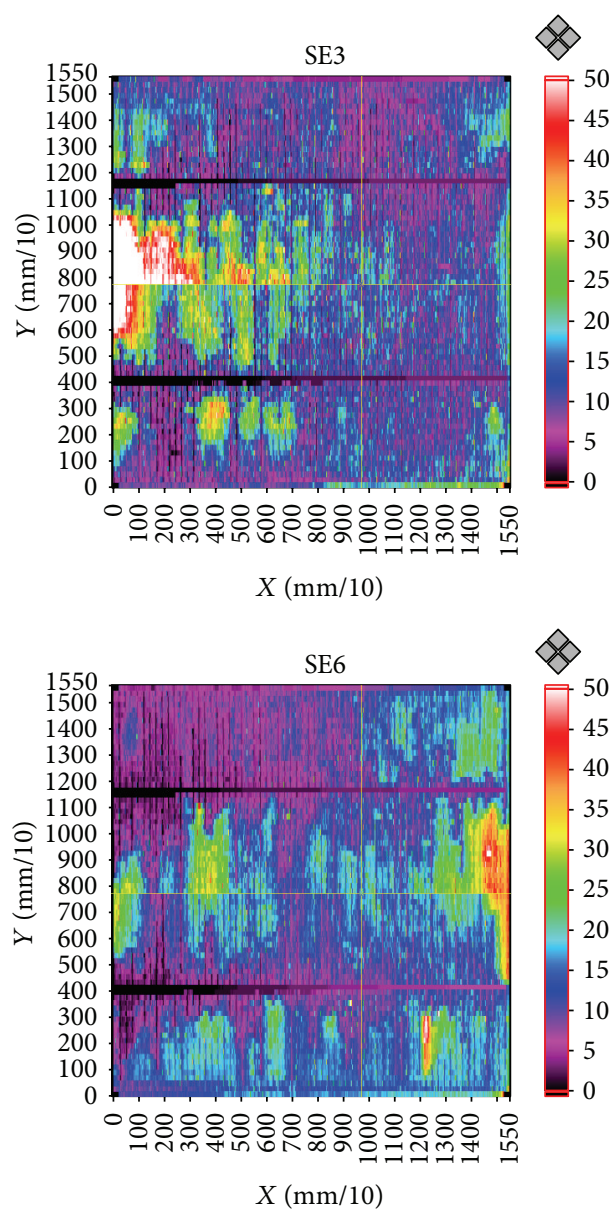

FIGURE 9: (a) Distribution profile for comparison with potential loss (in $\mathrm{mV}$ ) of the occupied minority carriers (in \%) and average values on the surface of the six SE samples and (b) corresponding real-distribution maps of potential loss profiles. The color chart description is the same as Figure 8(b). 
CMRPG 2B0541) of Taiwan, respectively. Mr. Sheng-Shih Wang especially appreciates the support of China University of Science and Technology (Taiwan).

\section{References}

[1] D. Kray and K. R. McIntosh, "Analysis of selective phosphorous laser doping in high-efficiency solar cells," IEEE Transactions on Electron Devices, vol. 56, no. 8, pp. 1645-1650, 2009.

[2] K. Misiakos and F. A. Lindholm, "Toward a systematic design theory for silicon solar cells using optimization techniques," Solar Cells, vol. 17, no. 1, pp. 29-52, 1986.

[3] M. J. Jackson and W. O’Neill, "Laser micro-drilling of tool steel using Nd:YAG lasers," Journal of Materials Processing Technology, vol. 142, no. 2, pp. 517-525, 2003.

[4] L. A. Dobrzański and A. Drygała, "Surface texturing of multicrystalline silicon solar cells," Journal of Achievements in Materials and Manufacturing Engineering, vol. 31, no. 1, pp. 7782, 2008.

[5] M. Naumann and F. Kirscht, "Investigation of defect structures in multi-crystalline silicon by laser scattering tomography," Thin Solid Films, vol. 487, no. 1-2, pp. 188-192, 2005.

[6] D. Kray, M. Aleman, A. Fell et al., "Laser-doped silicon solar cells by Laser Chemical Processing (LCP) exceeding 20\% efficiency," in Proceedings of the 33rd IEEE Photovoltaic Specialists Conference (PVSC '08), pp. 1-3, San Diego, Calif, USA, May 2008.

[7] S. R. Wenham and M. A. Green, "Laser grooved solar cell," US Patent, 4,626,613, 1986.

[8] D. Kray, A. Fell, S. Hopman, K. Mayer, G. P. Willeke, and S. W. Glunz, "Laser Chemical Processing (LCP) - a versatile tool for microstructuring applications," Applied Physics A: Materials Science and Processing, vol. 93, no. 1, pp. 99-103, 2008.

[9] J.-J. Ho, Y.-T. Cheng, J.-J. Liou et al., "Advanced selective emitter structures by laser opening technique for industrial mc-Si solar cells," Electronics Letters, vol. 46, no. 23, pp. 1559-1561, 2010.

[10] S. Wenham, "Burried-contact solar cells," Progress in Photovoltaics, vol. 1, no. 1, pp. 3-10, 1993.

[11] J. Szlufcik, H. E. Elgamel, M. Ghannam, J. Nijs, and R. Mertens, "Simple integral screenprinting process for selective emitter polycrystalline silicon solar cells," Applied Physics Letters, vol. 59, no. 13, pp. 1583-1584, 1991.

[12] T. Fellmeth, S. MacK, J. Bartsch et al., "20.1\% efficient silicon solar cell with aluminum back surface field," IEEE Electron Device Letters, vol. 32, no. 8, pp. 1101-1103, 2011.

[13] R. Schindler, A. Breymesser, H. Lautenschlager, C. Marckmann, S. Noeel, and U. Schubert, "Single step rapid thermal diffusion for selective emitter formation and selective oxidation," in Proceedings of the 25th IEEE Photovoltaic Specialists Conference, pp. 509-512, Washington, DC, USA, May 1996.

[14] P. J. Cousins, C. B. Honsberg, and J. E. Cotter, "Single high temperature step selective emitter structures using spin-on dopant sources," in Proceedings of the Conference Record 29th IEEE Photovoltaic Specialists Conference, pp. 281-284, New Orleans, La, USA, May 2002.

[15] S.-S. Wang, J.-J. Ho, J.-J. Liou et al., "Performance improvements of selective emitters by laser openings on large-area multicrystalline Si solar cells," International Journal of Photoenergy, vol. 2014, Article ID 291904, 8 pages, 2014.

[16] G. Scardera, D. Poplavskyy, M. Abbott, and F. Lemmi, "Highly tunable single step selective emitter diffusion process using silicon ink technology," in Proceedings of the 37th IEEE Photovoltaic
Specialists Conference (PVSC '11), pp. 2202-2205, Seattle, Wash, USA, June 2011.

[17] Y.-T. Cheng, J.-J. Ho, W. J. Lee et al., "Investigation of low-cost surface processing techniques for large-size multicrystalline silicon solar cells," International Journal of Photoenergy, vol. 2010, Article ID 268035, 6 pages, 2010.

[18] A. Kress, R. Tölle, T. Bruton, P. Fath, and E. Bucher, "10×10 $\mathrm{cm}^{2}$ screen printed back contact cell with a selective emitter," in Proceedings of the 28th IEEE Photovoltaic Specialists Conference, pp. 213-216, Anchorage, Alaska, USA, 2000.

[19] M. J. Kerr, J. Schmidt, A. Cuevas, and J. H. Bultman, "Surface recombination velocity of phosphorus-diffused silicon solar cell emitters passivated with plasma enhanced chemical vapor deposited silicon nitride and thermal silicon oxide," Journal of Applied Physics, vol. 89, no. 7, pp. 3821-3826, 2001.

[20] A. R. Jha, Solar Cell Technology and Applications, CRC Press, Taylor \& Francis Group, LLC, Boca Raton, Fla, USA, 2010.

[21] C.-H. Lin, S.-P. Hsu, J.-J. Liou, C.-P. Chuang, W.-H. Lu, and W.-L. Chang, "Characterization of selective-emitter solar cells consists of laser opened window and subsequently screenprinted electrodes," in Proceedings of the 35th IEEE Photovoltaic Specialists Conference (PVSC '10), pp. 3523-3526, Honolulu, Hawaii, USA, June 2010.

[22] S. Fonash, Solar Cell Device Physics, Academic Press, Burlington, Mass, USA, 2nd edition, 2010.

[23] M. Tucci, L. Serenelli, A. D. Bono et al., "Plasma dry etching for selective emitter formation in crystalline silicon based solar cell," in Proceedings of the Conference on Optoelectronic and Microelectronic Materials and Devices (COMMAD '08), pp. 273276, Sydney, Australia, August 2008. 

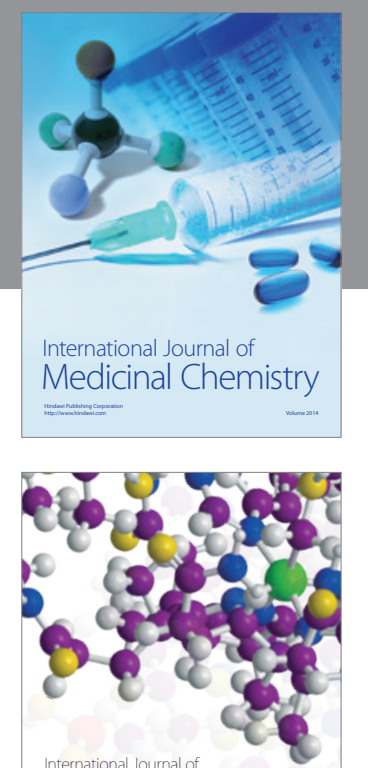

\section{Carbohydrate} Chemistry

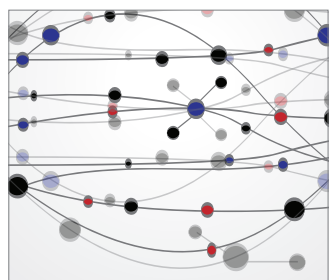

The Scientific World Journal
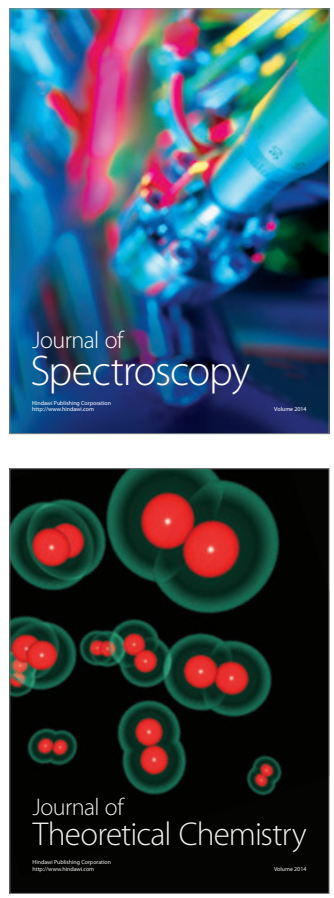
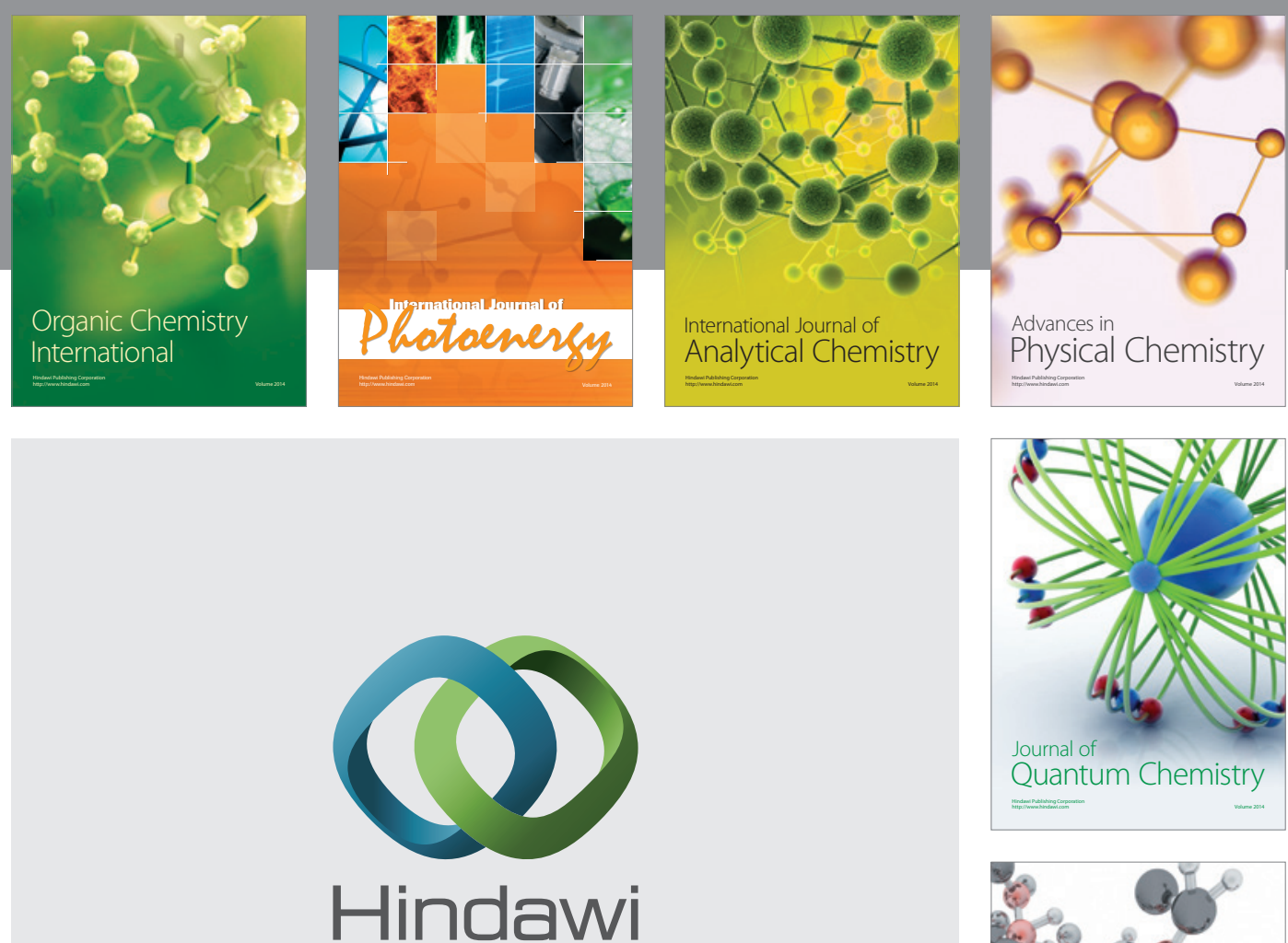

Submit your manuscripts at

http://www.hindawi.com

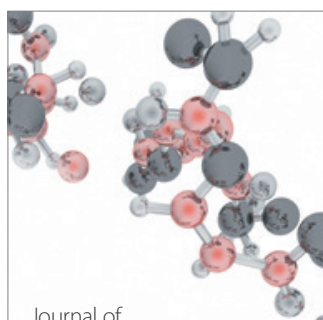

Analytical Methods

in Chemistry

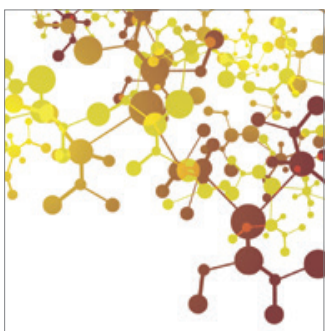

Journal of

Applied Chemistry

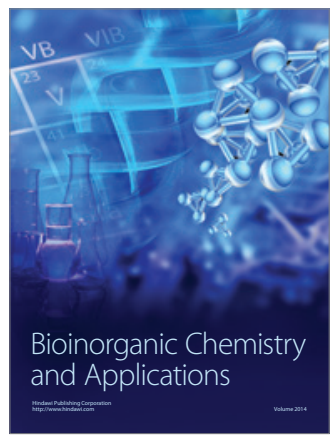

Inorganic Chemistry
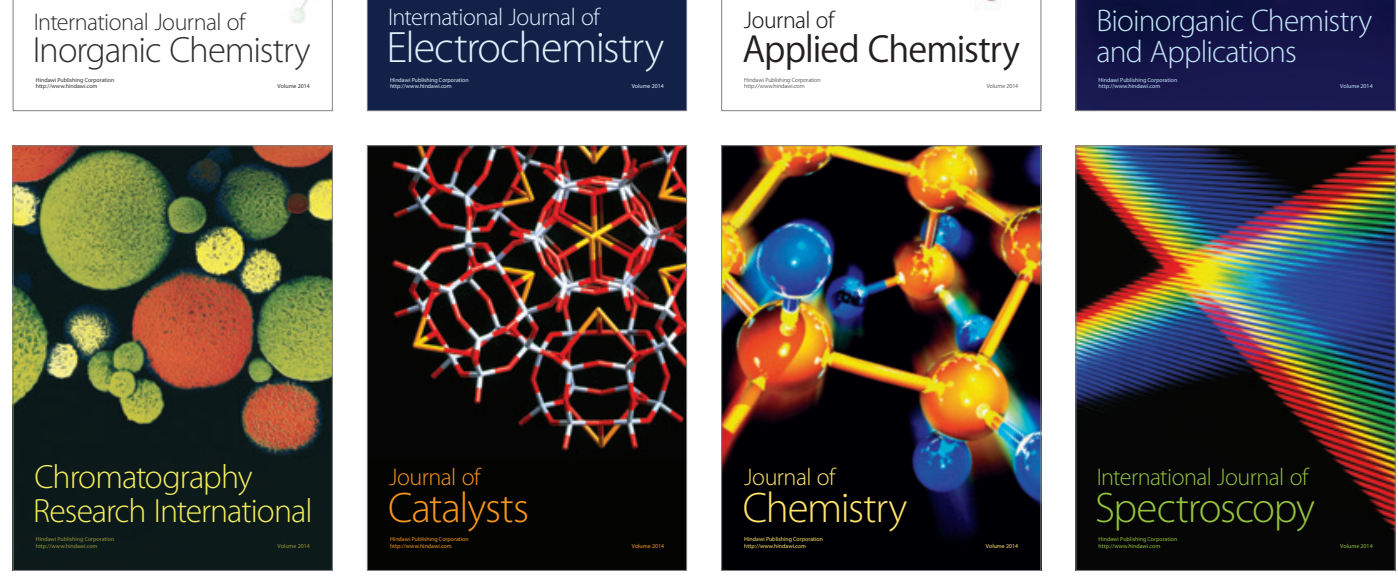